\title{
Autoevaluación y reflexión docente para la mejora de la competencia profesional del profesorado en la sociedad del conocimiento
}

\section{Teacher self-assessment and reflection to improve teachers' professional competence in the knowledge society}

\author{
Miryam Martínez-Izaguirre \\ Universidad de Deusto, Bilbao (España) \\ miryam.martinez@deusto.es \\ Concepción Yániz-Álvarez de Eulate \\ Universidad de Deusto, Bilbao (España) \\ cyaniz@deusto.es \\ Lourdes Villardón-Gallego \\ Universidad de Deusto, Bilbao (España) \\ lourdes.villardon@deusto.es
}

\begin{abstract}
Resumen
Ante los retos que entraña vivir en la sociedad del conocimiento, la educación obligatoria ha de velar por el desarrollo de ciudadanos responsables, competentes y comprometidos con la mejora de su entorno. Este objetivo exige la reconceptualización de la labor del docente y contar con profesorado implicado en el desarrollo de competencias docentes que le permitan un ejercicio eficaz de sus funciones.

Los procesos de autoevaluación y reflexión suponen una oportunidad para favorecer caminos hacia el desarrollo profesional y la mejora. Asimismo, las TIC revelan amplias posibilidades en la implementación de las competencias docentes en la medida en la que se integran de manera transversal y al servicio de la acción docente, facilitando el desempeño de sus tareas.

A continuación, por tanto, se presenta el diseño de la Escala de evaluación de las competencias docentes del profesorado de educación obligatoria, orientada a promover la reflexión sobre la importancia y aplicación de las competencias docentes en el escenario educativo actual. Su empleo tiene importantes implicaciones en el desarrollo profesional docente y en su avance hacia la competencia profesional.
\end{abstract}

Palabras clave: TIC, competencias docentes, autoevaluación docente, reflexión docente, desarrollo profesional. 


\begin{abstract}
Faced with the challenges posed by the knowledge society, compulsory education must ensure to produce responsible, competent citizens committed to improving their environment. This aim requires re-thinking teachers' work and having a teaching staff involved in the development of teaching competences that will allow them to effectively perform their tasks.

Self-assessment and reflection processes are an opportunity to promote paths towards professional and improvement processes. Likewise, ICTs provide ample possibilities to implement teachers' competences provided that they are transversally incorporated to enhance teaching, thus facilitating the performance of their tasks.

Then, the design of the Teaching competence assessment scale for compulsory education teachers is presented, aimed at promoting reflection on the importance and application of teaching competences in today's educational scenario. Its application has major implications for teachers' professional development and for their progress towards professional competence.
\end{abstract}

Key words: ITC, teaching competences, teaching self-assessment, teachers' reflection, professional development.

\title{
Introducción
}

La sociedad actual, marcada por el avance imparable del conocimiento, la globalización, las situaciones de pobreza e injusticia social, así como por un desarrollo necesariamente sostenible, se muestra desafiante ante la escuela y el profesorado.

La incorporación de las TIC en la vida cotidiana y el imparable crecimiento de la información y el conocimiento han puesto en jaque en los últimos años el paradigma educativo vigente, imposibilitando el mantenimiento de estilos educativos orientados a la asimilación del conocimiento existente, para avanzar hacia planteamientos en los que se hace preciso valorarlo, comprenderlo, analizarlo e integrarlo (Escudero y Correa, 2006). El replanteamiento de las finalidades educativas deriva en la implantación de un enfoque educativo basado en el desarrollo competencias que permiten al alumnado manejarse en esta sociedad cambiante haciendo un uso estratégico del conocimiento que construye.

En este proceso, se transforma la visión del aula como único espacio para la adquisición de conocimientos, y del profesor como fuente principal de acceso a la información, para convertirse hoy en día, las TIC, en el mejor aliado para el tratamiento de la información y la adquisición de conocimiento tanto para el alumnado como para el profesorado (Marzo, Esteban y Gargallo, 2006); y el docente, en un profesional de la educación obligado a reconstruirse (Montero y Gewerc, 2010) para seguir siendo útil en su contribución a la formación de ciudadanos libres y preparados para vivir en una sociedad cambiante (Vila y Casares, 2009; Zabala y Arnau, 2007).

Autoevaluación y reflexión docente para la mejora de la competencia profesional del profesorado en la sociedad del conocimiento. Martínez-Izaguirre, M.; Yániz-Álvarez de Eulate, C. y Villardón-Gallego, L. 
Aunque en ocasiones el avance tecnológico se percibe desde los centros educativos y el profesorado como un problema al que hacer frente (Tirado-Morueta y Aguaded-Gómez, 2014), las TIC están dando muestras de ofrecer amplias posibilidades de mejora del entorno educativo. Se convierten en aliadas y en recursos de utilidad para desempeñar funciones docentes que redundan en la mejora de la calidad educativa. Por un lado, en aquellas más directamente relacionadas con los procesos de aprendizaje, optimizando trabajos grupales, mejorando la motivación, el trabajo autónomo, la individualización del aprendizaje, así como simulando espacios para promover la transferencia de los aprendizajes realizados (Tejada, Jurado, Navío, y Ruiz Bueno, 2007). Por otro lado, facilitando el desempeño de funciones complementarias, como la coordinación docente, la colaboración con las familias y la comunidad, reduciendo la distancia física y favoreciendo entornos para comunicar y discutir ideas, así como para compartir proyectos de acción (Cacheiro, 2011).

\section{Desarrollo profesional del docente para educar en una sociedad cambiante}

Se constata que las dificultades observadas en la adecuación de las oportunidades que ofrece la tecnología en la educación del alumnado de educación básica no se reducen a las provocadas por el manejo propiamente de los dispositivos al alcance del profesorado, sino que van más allá. Parecen derivarse, en parte, de las actitudes y percepciones que éste tiene de sus funciones y de las acciones que debe desempeñar en el momento educativo actual. Esta idea se refleja en las palabras de Tirado-Morueta y Aguaded-Gómez (2014) al afirmar que las creencias del profesorado y su intención y conciencia pedagógica influyen de manera directa sobre el aprovechamiento de la tecnología.

Parece necesario, por tanto, atender a las percepciones que tiene el profesorado sobre las funciones que debe desempeñar y las competencias que moviliza en su quehacer diario, avanzar en la reconfiguración de la profesión docente en el escenario social actual para situarse ante un óptimo aprovechamiento de los recursos que la sociedad tecnológica pone al servicio de la profesión docente.

La permanente necesidad de mejora de la acción docente, unida a las exigencias más acuciantes de la sociedad del conocimiento ponen de manifiesto una necesaria revisión y reflexión sobre las competencias docentes que se ponen en juego para preparar al alumnado.

Este hecho, así como la integración y consolidación en los últimos años del enfoque educativo basado en el desarrollo de competencias en la educación obligatoria, provocan el replanteamiento de los contextos educativos empleados por los docentes y la apuesta por apoyar al profesorado en su desarrollo profesional y en la movilización de competencias que permitan respuestas educativas eficaces, manejando estratégicamente tanto los recursos pedagógicos como tecnológicos que dispone a su alcance (García-

Autoevaluación y reflexión docente para la mejora de la competencia profesional del profesorado en la sociedad del conocimiento. Martínez-Izaguirre, M.; Yániz-Álvarez de Eulate, C. y Villardón-Gallego, L. 
Peñalvo y Ramírez Montoya, 2017; Sánchez Prieto, Olmos Migueláñez, y GarcíaPeñalvo, 2017).

La constatación de la conveniencia de su desarrollo profesional y la mejora de sus competencias docentes ha derivado en dos acciones de relevancia: en la redefinición de la formación tanto inicial como permanente del profesorado, alineada con las funciones y desafíos que debe abordar en la actualidad; y en el replanteamiento del modo de fomentar su desarrollo profesional (Lieberman y Wilkins, 2006). En torno a esta última, los modelos estudiados advierten que la reflexión sobre la acción docente, sobre el nivel de competencia y su movilización es un paso imprescindible para su logro (Altet, 2005); (Charlier, 2005), para la implementación del modelo educativo vigente, así como para la orientación del profesorado hacia la mejora de sus actuaciones en el desempeño de sus funciones (Rueda, 2009).

Sin embargo, parecen insuficientes los recursos disponibles para evaluar en qué medida el profesorado presente en los centros escolares se sitúa en sintonía con las acciones a llevar a cabo para velar por una educación que oriente al alumnado hacia la vida y a su integración en la sociedad.

\section{La evaluación como proceso para la mejora de la calidad docente}

La denominada "generación de la evaluación para la calidad", movimiento de gran calado e instaurado en los últimos años, ha promovido el desarrollo de una cultura de evaluación centrada en la mejora de la educación (Aquino, Izquierdo y Echalaz, 2013; Araya y Vargas, 2013; Coloma, 2010; Vázquez Atochero y Romero Blanco, 2014). Siendo el docente pieza clave en la mejora de la calidad educativa, han sido constantes los esfuerzos realizados en evaluar su figura.

Sin embargo, estas evaluaciones viven momentos difíciles al instaurarse como una obligación o requerimiento ligado a cuestiones de certificación (Lieberman y Wilkins, 2006), y por perder de vista elementos esenciales en ella:

- El docente no ha sido sujeto activo en el análisis de su realidad y menos en la construcción de los senderos hacia su mejora. Han sido habituales los modelos centrados en el perfil del maestro orientados a evaluar su desempeño mediante escalas construidas en base a perfiles establecidos sin la consulta ni la colaboración de los principales implicados (Díaz Alcáraz, 2007).

- Los modelos centrados en resultados, encargados de evaluar el trabajo docente a partir de las producciones del alumnado, han perdido de vista que existen variables que también condicionan el aprendizaje como factores personales, escolares, socioambientales o familiares, entre otras (De Ketele, 2009; Escudero, Cutanda, y Trillo, 2017; Marchesi, 2000).

Autoevaluación y reflexión docente para la mejora de la competencia profesional del profesorado en la sociedad del conocimiento. Martínez-Izaguirre, M.; Yániz-Álvarez de Eulate, C. y Villardón-Gallego, L. 
- Los modelos centrados en las actuaciones docentes en el aula, orientados a evaluar al profesorado en base a sus comportamientos, han obviado que, dependiendo del evaluador, las actuaciones y comportamientos eficaces podían ser diferentes, y que los entornos empleados para el aprendizaje pueden superar las barreras del aula.

Ante estas dificultades, destacan las propuestas de evaluación basadas en la práctica reflexiva, defendida por Schön (1983), pues centran el foco en la mejora de la práctica y en la relevancia del papel activo del docente sobre ella, además de dejar a un lado el control y la rendición de cuentas (Altet, 2005; Charlier, 2005).

\section{La autoevaluación y la reflexión para la mejora de las competencias docentes}

Mejorar la competencia profesional requiere incorporar la reflexión y la evaluación de la docencia (García Ramos y Congosto, 2000; Jerónimo Montes, 2003; Ruyter y Kole, 2010), a través del diseño de un sistema que permita analizar la percepción del profesorado sobre su nivel de competencia para llevar a cabo con rigor y profesionalidad sus funciones docentes (Muñoz Cantero, Rios de Deus y Abalde, 2002).

Poner en práctica propuestas de autoevaluación además de resultar enriquecedor y respetuoso con la autonomía profesional docente, permitirá al propio profesorado autodirigirse hacia su desarrollo profesional. Y aunque conviene regularlo, es aún más importante que el colectivo docente esté convencido de la necesidad de desarrollarse profesionalmente a lo largo de toda su carrera. La tendencia a asociar los procesos de evaluación con control o fiscalización y las resistencias que ello genera (Díaz Alcáraz, 2007), exige el máximo cuidado en el diseño de las evaluaciones, contemplando positivamente a sus principales actores e involucrándoles en el proceso. Los profesores necesitan oportunidades para mejorar y quieren hacerlo, pero para ello necesitan información, sentirse motivados, recursos y colaboración para asumir su responsabilidad en la mejora de sus competencias y en su crecimiento profesional (Airasian y Gullickson, 1998).

Los modelos basados en la autoevaluación implican de manera positiva a los protagonistas, los convierten en agentes activos del proceso de evaluación y exigen en ellos un esfuerzo de reflexión (Altet, 2005; Muñoz Cantero et al., 2002). Esta implicación positiva permite encadenar procesos de mejora, convirtiendo a la autoevaluación del profesorado en un proceso de evaluación para desarrollar sus competencias (Daoud, 2007; McCoskey y Egelson, 1993; citados por Airasian y Gullickson, 1998); que favorece la generalización de la mejora al centro educativo y a los aprendizajes de los escolares (Bolancé, Cuadrado, Ruiz Suárez y Sánchez Velasco, 2013). Son destacables también otros beneficios: desarrolla procesos de revisión interna de los centros, facilita evidencias sobre las actuaciones docentes ante la comunidad

Autoevaluación y reflexión docente para la mejora de la competencia profesional del profesorado en la sociedad del conocimiento. Martínez-Izaguirre, M.; Yániz-Álvarez de Eulate, C. y Villardón-Gallego, L. 
educativa, incentiva y motiva a los docentes articulando una carrera docente y legitima el propio sistema educativo (Díaz Alcáraz, 2007).

No obstante, conviene que la autoevaluación sea complementada con otro modelo de evaluación, para evitar sesgos y ofrecer la oportunidad al docente de revisar aspectos que desde su posición no son observables (Aquino et al.; 2013; Elizalde y Reyes, 2008; Muñoz y Biel, 2008).

\section{Elementos sobre los que centrar la evaluación}

La revisión de los instrumentos de evaluación docente empleados hasta el momento muestra también diferentes enfoques (Muñoz Cantero et al., 2002; Valdivieso, Carbonero y Martín-Antón, 2013). Algunos de ellos, centrados en estudiar la percepción de los docentes sobre su práctica y su visión de la enseñanza como The Teaching Perspectives Inventory (Pratt y Collins, 2000; Pratt, Collins y Jarvis Selinger, 2001), o la propuesta de análisis de estilos de enseñanza del profesorado como The Teaching Style Inventory (CORD, 2005). Otros ponen el foco de atención en la efectividad de la formación como The Teacher Belief Inventory (Nottis, Feuerstein, Murray y Adams, 2000). Se aprecian también interesantes aportaciones para la evaluación de la satisfacción profesional de los docentes ante las tareas y funciones relativas a la enseñanza y a las relaciones y gestiones dentro de la institución escolar, como es el caso del Cuestionario de satisfacción profesional docente (Padrón Hernández, 1994). Los instrumentos elaborados para la evaluación del desempeño se centran fundamentalmente en el análisis de los procesos de enseñanza -aprendizaje y en los estilos de enseñanza, como la Escala CAPE - Cuestionario de autoevaluación del proceso de enseñanza (Barca, Peralbo, Brenlla y Seijas, 2006) y las Escalas para la evaluación interactiva de proceso de enseñanza-aprendizaje - EIPEA (De la Fuente y Martínez Vicente, 2004).

Son destacables también los instrumentos que facilitan la autoevaluación docente en su papel de favorecer el aprendizaje como es el caso de La autoevaluación del profesor (Nieto, 1994), El sistema de autoevaluación para el profesorado de Educación Secundaria Obligatoria (Solabarrieta, 1997), El sistema de autoevaluación y mejora para el profesorado de Educación Primaria (Yániz, 1998), la Escala para la autoevaluación de la práctica docente (Díaz Alcáraz, 2007) o la Escala de Estrategias Docentes para Aprendizajes Significativos (EEDAS) (Méndez Hinojosa y González Ramírez, 2011), que ponen el acento en el papel activo del docente en el proceso y en la necesidad de atender a aspectos no sólo centrados en los procesos de aula, sino en otros relativos a la colaboración con otros agentes y en aquellos que favorecen el desarrollo profesional.

Pocos instrumentos incluyen las variables personales o profesionales definitorias de la calidad docente (Valdivieso et al., 2013). De la misma manera que los modelos de

Autoevaluación y reflexión docente para la mejora de la competencia profesional del profesorado en la sociedad del conocimiento. Martínez-Izaguirre, M.; Yániz-Álvarez de Eulate, C. y Villardón-Gallego, L. 
evaluación aportados por la investigación didáctica han evolucionado desde una focalización en la personalidad del profesor y su comportamiento, hacia una mayor preocupación por procesos indirectos que influyen en su actuación docente como su pensamiento o el contexto en el que desarrolla su actividad (Rodríguez Carbajal y Vera, 2007), en estos momentos parece necesario avanzar y contemplar su percepción también sobre el resto de actuaciones necesarias en el docente en relación a su participación en la organización y funcionamiento del centro, en lo relativo a su coordinación para la implementación de proyectos conjuntos, así como su relación con el entorno y familias, así como en incidir en la relevancia de su reflexión para la orientación de procesos de mejora en su docencia.

Se comprueba, por tanto, la existencia de elementos y competencias fundamentales en la docencia que quedan pendientes de evaluar y que se resumen en la necesidad de identificar las actuaciones que caracterizan a un buen docente más allá de los procesos de enseñanza-aprendizaje que se producen dentro del contexto de aula.

Dentro de esta perspectiva se centran el Instrumento de autoevaluación de competencias docentes para el profesorado de Formación Profesional para favorecer su desarrollo profesional (Hernández Prudencio y Sarramona, 2002) así como los trabajos realizados por García, Loredo, Luna y Rueda (2008), que diseñan una herramienta de evaluación de las competencias docentes que atiende no sólo al plano de aula, sino también al institucional. En este caso, aunque se tiene en cuenta la función docente desde un punto de vista amplio, que desarrolla funciones y tareas dentro del marco de una institución educativa, se mantiene en el modelo de evaluación adoptado el análisis del contexto, por un lado; y la evaluación de las competencias docentes propiamente dichas en el plano más concreto y relacionado con los procesos de aprendizaje.

Prevalece, por tanto, la necesidad de avanzar en la mejora de los instrumentos empleados para la evaluación de las competencias docentes hacia la contemplación de las diferentes funciones y dimensiones que supone la acción docente en el seno de una institución escolar.

El diseño de instrumentos de evaluación de competencias docentes contribuye a:

- Evaluar un mayor número de atributos y características necesarias para el ejercicio eficaz de la profesión.

- Hacer públicas las funciones que debe desempeñar el colectivo docente y lo que se espera de ellos.

- Aportar metas claras para la formación y preparación de profesionales de la educación y su ajuste a las demandas de una sociedad cambiante.

Autoevaluación y reflexión docente para la mejora de la competencia profesional del profesorado en la sociedad del conocimiento. Martínez-Izaguirre, M.; Yániz-Álvarez de Eulate, C. y Villardón-Gallego, L. 


\section{Las competencias docentes, objeto de autoevaluación y reflexión}

El enfoque educativo basado en competencias y las concepciones constructivistas del aprendizaje sobre los que se sustenta la propuesta, muestran la amplitud que toman las funciones del docente, y aumentan el radio sobre el que es preciso reflexionar, haciendo contemplar aquellas acciones que se generan no sólo en el aula, sino en el seno de la comunidad educativa para velar por la formación plena del alumnado como ciudadanos y para la vida. Son complejos los escenarios y diversos los colectivos con los que el docente deberá aunar esfuerzos para lograr las finalidades educativas del siglo XXI, exhortándole al desarrollo y movilización de competencias docentes. Todo ello hace preciso construir y disponer de modelos que favorezcan la autoevaluación y la reflexión sobre las competencias docentes, que cumplan una función diagnóstica y formativa, que permitan identificar las posibles debilidades existentes en la práctica de los actuales docentes con la intención de establecer las medidas y apoyos necesarios para su mejora (Araya y Vargas, 2013; Garrido y Fuentes, 2008).

Parece conveniente desarrollar modelos que valoren de manera cuantitativa las tendencias y disposiciones del profesorado, sus patrones conductuales, así como las habilidades y destrezas que les diferencian (Hervás, 2003). Es decir, se trata de superar el análisis de las actividades cognitivas que se encuentra en la base de las acciones de los docentes, para estudiar y evaluar su pensamiento, concepciones, creencias y acciones directas, sus conocimientos, así como la reflexión que hacen sobre su forma de ejercer la profesión. De este modo la autoevaluación de la competencia docente se posiciona como medio recomendable para evaluar el desempeño docente, en el que toman papel activo un paquete de competencias (Valdivieso et al., 2013), materializadas en recursos, habilidades, actitudes y conocimientos relacionados con la instrucción, la gestión emocional, las relaciones e interacciones sociales y la motivación (Pena, Rey y Extremera, 2012).

Una de las mayores dificultades que aborda la evaluación de las competencias docentes es su multidimensionalidad y la polémica que supone la selección de los indicadores para analizar el desempeño docente. Aunque existen elementos macroestructurales marcados por las políticas educativas, han de seleccionarse los más significativos de la práctica docente eficaz (Elizalde y Reyes, 2008).

Las variables más recurrentes se han centrado en la organización, planificación, la metodología de enseñanza, las actitudes del profesorado, las interacciones con el alumnado (Abbott y Perkins, 1978; Doyle, 1975; Linn et al., 1975; Marsh, 1984; Marsh y Overall, 1980; Trent y Cohen, 1973; Overall y Marsh, 1977; Whitely y Doyle, 1976; citados por Muñoz Cantero et al., 2002). El peso de la tradición se aprecia al comprobar que la competencia docente se tiende a evaluar en base a las conductas relacionadas con los procesos de enseñanza aprendizaje propiciados en el aula. Sin embargo, se observa cierto avance en las dimensiones señaladas por Escudero (1996), Mateo et al. (1995),

Autoevaluación y reflexión docente para la mejora de la competencia profesional del profesorado en la sociedad del conocimiento. Martínez-Izaguirre, M.; Yániz-Álvarez de Eulate, C. y Villardón-Gallego, L. 
Mateo, Escudero, de Miguel, Ginés y Rodríguez (1996), recogidas por Muñoz Cantero et al. (2002), que introducen matices nuevos al determinar la importancia del análisis de competencias relacionadas con la docencia y la evaluación, así como de variables como la profesionalidad y el servicio a la comunidad, ajustando la evaluación de la actividad docente a la visión que en el actualidad se tiene de ésta.

En definitiva, parece necesario fijar un sistema de autoevaluación de competencias docentes que contemplen las diferentes funciones y escenarios de acción del profesorado. Habrá de tenerse en cuenta, por un lado, el aula (Díaz Alcáraz, 2007) y los entornos virtuales de aprendizaje (Zapata, 2015), incluyendo los procesos que se llevan a cabo en ellos, la relación con el alumnado, la planificación de la enseñanza, la gestión del clima de trabajo, la relación con las familias del alumnado o la atención a la diversidad del alumnado. Y, por otro lado, la gestión, que incluye la dedicación de los docentes al centro en cuestiones como la coordinación docente, la participación en órganos colegiados y de gobierno, en actividades complementarias y el desarrollo de proyectos de centro. Asimismo, se considera preciso tener en cuenta algunas características, habilidades o actitudes que orienten sus acciones favoreciendo su actuación desde la ética y bajo una gestión eficaz de las emociones que despiertan las diferentes situaciones e interacciones que se viven en el centro.

Para ello, se propone un estudio orientado al diseño de una escala de evaluación que favorezca el desarrollo docente. Éste parte, por tanto, de la necesidad de contar con la participación de los docentes en los procesos de construcción, reflexión y mejora de su perfil. Se basa por un lado en los modelos centrados en el perfil del maestro, ya que tiene en cuenta el perfil docente construido a partir de las aportaciones realizadas desde la investigación, el análisis de la realidad social y escolar y las necesidades educativas emergentes; contrastado con un grupo de expertos.

Asimismo, se basa en los modelos centrados en la práctica reflexiva favoreciendo momentos para la autoevaluación y la reflexión sobre su desempeño a través de la oportunidad que ofrece la Técnica de Análisis de la Importancia y la Realización AIR (Importance-Performance Analysis - IPA), para identificar y analizar en qué modo las prioridades y las acciones docentes se sitúan en un planos de máxima prioridad o de sobreesfuerzo. La fortaleza de esta técnica reside en la claridad con la que representa los datos a través de un eje de coordenadas (Martilla y James, 1977). Mientras en el eje de ordenadas se representa la importancia que los sujetos otorgan a un hecho, situación, dato..., en el eje de las abscisas, se indica en qué medida consideran los sujetos que tal cuestión se realiza (Ver Figura 1).

Autoevaluación y reflexión docente para la mejora de la competencia profesional del profesorado en la sociedad del conocimiento. Martínez-Izaguirre, M.; Yániz-Álvarez de Eulate, C. y Villardón-Gallego, L. 


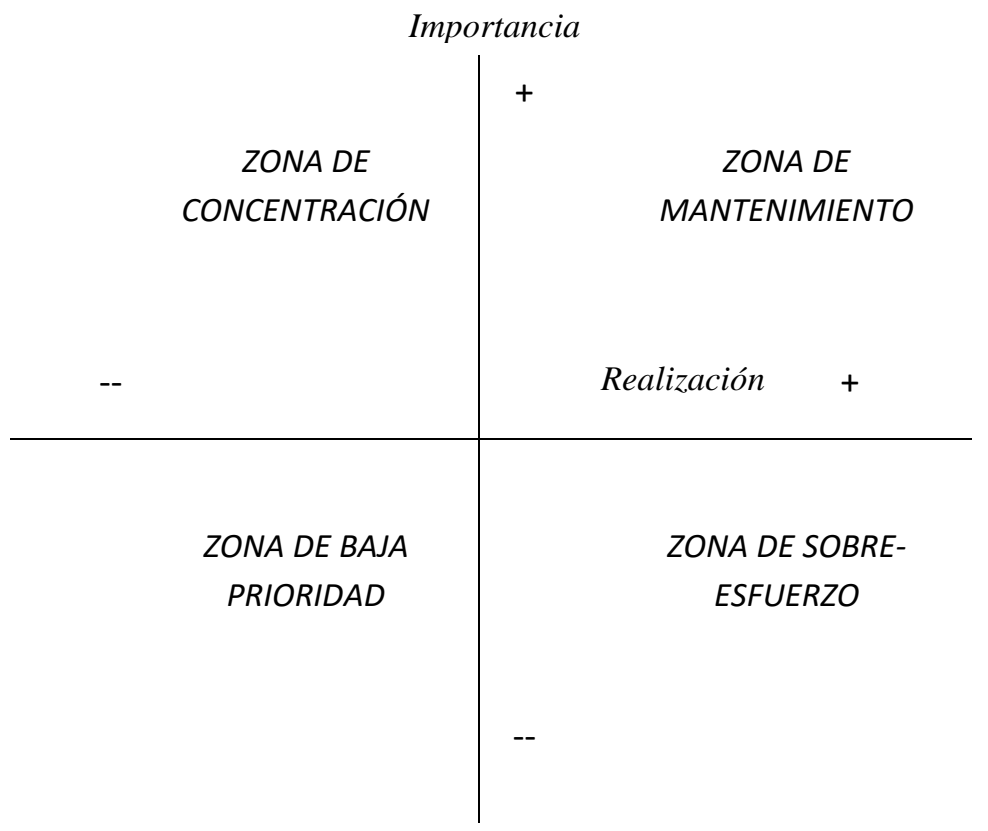

Figura 1. Representación clásica del Análisis de Importancia-Realización

Fuente: Tomado de Ábalo, Varela y Rial (2006)

El cruce del eje de coordenadas permite que las puntuaciones dadas por los sujetos puedan situarse en cuatro cuadrantes bien diferenciados:

- Área de concentración: Es un área de alta importancia, pero de baja realización. Se considera desajustada, pues los objetivos que se sitúan en ella son valorados como relevantes por los sujetos, sin embargo, son poco llevados a la práctica. En este sentido, serían aspectos a mejorar y sobre los que invertir mayor nivel de recursos y esfuerzos.

- Área de mantenimiento: Es un área de alta importancia y de alta realización. Los aspectos situados en este cuadrante son significativos por su importancia y por su realización. Por ello, los esfuerzos y recursos empleados están justificados y deben mantenerse.

- Área de baja prioridad: Es un área de baja importancia y baja realización. En esta zona, al igual que en el cuadrante anterior, el esfuerzo en la realización está ajustado a la importancia que tiene. Es decir, en este caso, las cuestiones sobre las que se pregunta a los sujetos se consideran poco importantes, y además, se realizan poco.

- Área de sobre-esfuerzo: Es un área de baja importancia, pero de alta realización. Al igual que en el área de concentración se observa un desajuste. En este caso, en ella se concentran los aspectos que han sido considerados poco importantes,

Autoevaluación y reflexión docente para la mejora de la competencia profesional del profesorado en la sociedad del conocimiento. Martínez-Izaguirre, M.; Yániz-Álvarez de Eulate, C. y Villardón-Gallego, L. 
sin embargo, se están empleando gran cantidad de esfuerzos y recursos para llevarlos a cabo. De ahí la necesidad de rebajar el nivel de dedicación a ellos, para poder invertir tales esfuerzos y recursos en objetivos que así lo merezcan, por ejemplo, aquellos situados en el área de concentración.

La lectura del cuadrante, resultante de la ubicación de las puntuaciones de la muestra en el eje de coordenadas, permitirá tener una visión clara del estado de la cuestión, así como plantear actuaciones estratégicas para orientar la mejora.

Todo ello, hace que la escala dote al profesorado de la oportunidad de contrastar sus prioridades educativas con sus actuaciones, dando como resultado un escenario que le ayude a detectar las líneas sobre las que proyectar sus esfuerzos.

\section{Método}

\section{Objetivos}

El objetivo de este estudio ha sido elaborar una escala de evaluación de competencias docentes, que permita al profesorado de educación básica detectar sus puntos fuertes y débiles, y les oriente hacia la mejora.

\section{Procedimiento}

La propuesta para la autoevaluación y mejora de las competencias docentes se ha basado en un perfil definido y validado previamente, acorde a las funciones a desempeñar en el contexto actual (Martínez-Izaguirre, Yániz-Álvarez de Eulate, y Villardón-Gallego, 2017). Se ha diseñado una escala de evaluación de las competencias docentes del profesorado de educación obligatoria, basada en el desempeño y que centra su evaluación tanto en el nivel de importancia otorgado por los docentes a las competencias asociadas a su perfil, como en su percepción sobre el nivel de aplicación en la práctica docente. Las competencias evaluadas son la Competencia para la planificación y gestión educativa, la Competencia para gestión e implementación del curriculum, la Competencia para la evaluación educativa, la Competencia en orientación y tutoría, la Competencia para el aprendizaje, la investigación y la innovación, la Competencia ética y el compromiso profesional, la Competencia para la coordinación y el trabajo en equipo, la Competencia para gestión emocional y la creación de un clima de confianza y la Competencia para la comunicación con los agentes de la comunidad educativa.

El diseño de la escala permite que los resultados de la evaluación se analicen aplicando la Técnica de Análisis de la Importancia y la Realización AIR, creada por Martilla y James en 1977, determinando el nivel de discrepancia entre los aspectos valorados y

Autoevaluación y reflexión docente para la mejora de la competencia profesional del profesorado en la sociedad del conocimiento. Martínez-Izaguirre, M.; Yániz-Álvarez de Eulate, C. y Villardón-Gallego, L. 
aquello que se lleva a cabo en realidad, y extraer una fotografía de la práctica percibida por cada docente con una serie de recomendaciones para su mejora.

Para su diseño ha sido necesario el empleo de técnicas tanto de carácter cualitativo como cuantitativo. Por un lado, el juicio de expertos, con la intención de analizar la validez de contenido la escala, y por otro, la aplicación Piloto, que posibilita el análisis de la fiabilidad de la escala por medio del coeficiente Alfa de Cronbach.

Este trabajo se ha abordado a través del seguimiento y cumplimiento de las fases que se detallan a continuación

\section{FASE 1: Diseño preliminar de la escala de evaluación de competencias docentes}

Partiendo de una revisión inicial sobre los modelos e instrumentos existentes para la evaluación de la calidad docente y de sus competencias, y analizada la pertinencia, bonanza y desventajas de cada uno de ellos, se procedió al diseño preliminar de la escala. Su construcción partió de una serie de premisas. La escala debía:

- Posibilitar la realización de evaluaciones ágiles, eficaces y promotoras de la mejora y desarrollo docente.

- Medir las competencias asociadas al perfil docente de educación obligatoria actual.

- Estar basada en el desempeño docente, reflejando los ítems acciones vinculadas a las competencias asociadas al perfil.

- Posibilitar conocer la importancia otorgada por el profesorado a las competencias docentes y la identificación de su nivel de aplicación.

Siguiendo estos criterios se diseñó una escala de autoevaluación docente de doble entrada, que permitía valorar en un rango de 1 a 5 , tanto la importancia como la realización de cada una de las acciones recogidas en los ítems del instrumento. Este diseño, abría la posibilidad de realizar posteriormente análisis de la discrepancia entre importancia y realización, por medio de la aplicación de técnicas como AIR, diseñada por Martilla y James (1977).

Para garantizar la coherencia entre el instrumento y el perfil docente, se hizo una búsqueda de acciones y situaciones que evidenciaran en el profesorado la movilización de cada una de las dimensiones asociadas a las competencias docentes.

Tras una propuesta inicial sobre las dimensiones a evaluar y los ítems a emplear, y una posterior depuración, se construyó un instrumento preliminar.

FASE 2: Juicio de Expertos

Autoevaluación y reflexión docente para la mejora de la competencia profesional del profesorado en la sociedad del conocimiento. Martínez-Izaguirre, M.; Yániz-Álvarez de Eulate, C. y Villardón-Gallego, L.

Página 12 de 30 
Con el fin de validar la estructura y el contenido del instrumento, se llevó a cabo el juicio de expertos. Para ello, se presentó a un grupo de 8 jueces, expertos en investigación, evaluación educativa y en formación inicial y permanente de profesorado, una plantilla con las competencias docentes, sus principales dimensiones y los ítems propuestos para su medición. En ella, debían valorar sobre cada ítem la adecuación a la dimensión, la claridad de la formulación y, si procedía, podían hacer sugerencias de formulación u observaciones.

Un análisis descriptivo de las respuestas otorgadas por los expertos sobre el nivel de adecuación de los ítems a las competencias, así como la claridad en su formulación arrojó los resultados que se presentan en la Tabla 1.

\section{Tabla 1}

\section{Opinión de los expertos sobre los ítems incluidos en la escala preliminar}

\begin{tabular}{|c|c|c|c|c|}
\hline \multirow{2}{*}{ Competencias docentes } & \multicolumn{2}{|c|}{$\begin{array}{l}\text { Adecuación a la } \\
\text { competencia }\end{array}$} & \multicolumn{2}{|c|}{$\begin{array}{l}\text { Claridad de la } \\
\text { formulación }\end{array}$} \\
\hline & Media & Desv. Típ. & Media & Desv. Típ. \\
\hline $\begin{array}{l}\text { Competencia para la planificación y gestión } \\
\text { educativa. }\end{array}$ & 3,77 & 0,43 & 3,45 & 0,79 \\
\hline $\begin{array}{l}\text { Competencia para la gestión e } \\
\text { implementación del curriculum. }\end{array}$ & 3,85 & 0,31 & 3,62 & 0,60 \\
\hline Competencia para la evaluación educativa. & 3,86 & 0,31 & 3,60 & 0,73 \\
\hline Competencia en orientación y tutoría & 3,89 & 0,22 & 3,73 & 0,47 \\
\hline $\begin{array}{l}\text { Competencia para el aprendizaje y para la } \\
\text { investigación y la innovación }\end{array}$ & 3,75 & 0,52 & 3,65 & 0,62 \\
\hline Competencia ética y compromiso profesional & 3,79 & 0,38 & 3,61 & 0,70 \\
\hline $\begin{array}{l}\text { Competencia para la coordinación docente y } \\
\text { trabajo en equipo en la comunidad educativa }\end{array}$ & 3,76 & 0,52 & 3,67 & 0,59 \\
\hline $\begin{array}{l}\text { Competencia para la gestión eficaz de las } \\
\text { emociones y la creación de climas de } \\
\text { confianza }\end{array}$ & 3,78 & 0,38 & 3,86 & 0,33 \\
\hline Competencia para la comunicación & 3,82 & 0,42 & 3,76 & 0,48 \\
\hline TOTAL & 3,81 & 0,39 & 3,66 & 0,59 \\
\hline
\end{tabular}

Fuente: Elaboración propia

Autoevaluación y reflexión docente para la mejora de la competencia profesional del profesorado en la sociedad del conocimiento. Martínez-Izaguirre, M.; Yániz-Álvarez de Eulate, C. y Villardón-Gallego, L. 
Los expertos mostraron un grado de acuerdo elevado con la adecuación de los ítems para la medición de las competencias docentes $(\mathrm{M}=3,81 ; \mathrm{DT}=0,39)$. Asimismo, la claridad de la formulación de los ítems propuestos para medirlas también fue valorada de manera positiva $(M=3,66 ; \mathrm{DT}=0,59)$. Sin embargo, atendiendo a las observaciones realizadas y con el fin de mejorar aún más los valores de adecuación y claridad de los ítems, se llevó a cabo un proceso de depuración y mejora, dando como resultado la escala que se aplicó en el estudio piloto.

\section{FASE 3: Aplicación piloto}

Tras la incorporación de las aportaciones realizadas por los expertos y la mejora del instrumento en base a éstas, se procedió a su aplicación piloto en una muestra de profesorado de educación básica de la Comunidad Autónoma del País Vasco. Por medio de esta aplicación se lograban dos metas importantes: analizar la fiabilidad del instrumento y tener un resultado preliminar sobre la opinión del profesorado en torno a las competencias docentes que se les atribuyen.

El estudio piloto tenía como objetivo principal poner a prueba la escala creada para evaluar las competencias del profesorado de educación obligatoria, lo que se concreta en:

- Estudiar cómo respondía el profesorado ante la petición de respuesta de la escala.

- Comprobar el tiempo de dedicación para su respuesta y las posibles dificultades que surgieran en el proceso.

- Analizar la fiabilidad de la escala.

- Mejorar el instrumento.

Para proceder a su aplicación, se contactó con cuatro centros pertenecientes a la Comunidad Autónoma del País Vasco, tanto de la red pública como de la privada concertada, y que desarrollaban su labor educativa tanto en la Educación Primaria como en la Educación Secundaria Obligatoria (ESO), concretamente dos de ellos disponían de ambas etapas, mientras que uno de ellos sólo desarrollaba su labor en la etapa de Educación Primaria, y otro sólo en la ESO. Entre los cuatro centros tomaron parte un total de 57 profesores, de los cuales:

- El 59,6\% eran mujeres, frente al 40,4\% que eran hombres

- Respecto a la etapa educativa en la que desempeñaban su labor, el 15,8\% lo hacía en la Educación Primaria, el 80,7\% en la ESO y el 3,5\% en ambas. La razón de esta distribución de la muestra participante pueda encontrarse en las fechas en las que se realizó la aplicación piloto, concretamente entre mayo y junio, periodo en el que el profesorado de ESO ha finalizado en su mayoría las clases y dispone de mayor flexibilidad horaria, mientras que el profesorado de Educación Primaria se encuentra

Autoevaluación y reflexión docente para la mejora de la competencia profesional del profesorado en la sociedad del conocimiento. Martínez-Izaguirre, M.; Yániz-Álvarez de Eulate, C. y Villardón-Gallego, L. 
en la etapa final del curso, en plenas clases y procesos de evaluación, reunión con familias y tareas propias de este momento escolar, que dificultaron su colaboración.

- En relación a la formación pedagógica que disponían, el 15,8\% habían realizado estudios de Magisterio, el 63,2\% había cursado el Curso de Aptitud Pedagógica (CAP), el 3,5\% habían realizado el Máster de Educación Secundaria y el 17,5\% eran titulados en Pedagogía o Psicopedagogía.

La solicitud de colaboración se llevó a cabo a través del contacto con los equipos directivos de los centros, quienes facilitaron la presentación y difusión de la propuesta de participación entre su claustro de profesores. Desde un inicio, se planteó al profesorado como una participación voluntaria, anónima y se insistió en la confidencialidad de las respuestas dadas.

En la recogida de datos se emplearon dos métodos: un espacio web en el que cumplimentar directamente el cuestionario, y al que el profesorado podía acceder libremente; y una aplicación presencial en un espacio de reunión del centro.

Tras la aplicación se procedió al análisis estadístico de los resultados obtenidos en ella. Se llevaron a cabo análisis descriptivos, de frecuencias, así como de fiabilidad de las escalas y subescalas de importancia y realización a través del estudio del coeficiente Alfa de Cronbach.

\section{FASE 4: Depuración de la escala}

Las conclusiones obtenidas del estudio piloto y los resultados de los análisis estadísticos y de fiabilidad facilitaron el proceso de depuración de la escala. Teniendo en cuenta el Alfa de Cronbach y los datos que aportaba sobre la fiabilidad de la escala en caso de eliminar ítems, se procedió a su revisión, con el fin de mejorarla y simplificarla.

Junto a esta revisión, se hizo un nuevo esfuerzo de depuración de la formulación de algunos ítems, para facilitar y agilizar la lectura y comprensión del contenido al profesorado que respondiera la escala. De un total de 86 ítems en el instrumento aplicado en la prueba piloto se depuró hasta llegar a un total de 65 ítems en la escala definitiva.

Fase 5: Aplicación de la escala definitiva a una muestra del profesorado de educación obligatoria de Bizkaia

Con el fin de contrastar la fiabilidad de la escala resultante se aplicó sobre una muestra de la población conformada por los centros educativos de educación obligatoria de Bizkaia tanto públicos como privados concertados. Bizkaia cuenta con 439 centros de educación obligatoria. De este número total, y guardando su proporcionalidad por red y etapa educativa, se tomó un $10 \%$ de los centros. Así pues, la muestra fue conformada por un total de 44 centros. De ellos, el número de profesores que tomó parte fue de 559

Autoevaluación y reflexión docente para la mejora de la competencia profesional del profesorado en la sociedad del conocimiento. Martínez-Izaguirre, M.; Yániz-Álvarez de Eulate, C. y Villardón-Gallego, L. 
profesores. El 73,7\% fueron mujeres, frente al 26,3\% que fueron hombres. El 18,8\% era menor de 35 años; el 40,8\% tenía entre 36 y 50 años; y el 40,4\% entre 51 y 65 años. El $57,5 \%$ trabajaba en Educación Primaria, el 38,9\% en la ESO y el 3,6\% en ambas etapas. El 45,7\% disponía de Diplomatura, el 45,8\% de Licenciatura o Grado, el 7,9\% de Máster y el 0,5\% tenía título de Doctorado. El 58,7\% había estudiado Magisterio, el 22,9\% había realizado el Curso de Adaptación Pedagógica (CAP), el 1,3\% había llevado a cabo el Máster de Educación Secundaria y el 11,1\% contaba con formación psicopedagógica superior habiendo estudiado Pedagogía o Psicopedagogía. Asimismo, el 19,4 tenía menos de 10 años de experiencia docente, el 21,9\% entre 10 y 20 años, el $35,7 \%$ entre 21 y 30 años y el $23 \%$ entre 31 y 40 años de experiencia.

\section{Resultados}

Los análisis de fiabilidad llevados a cabo sobre la escala de importancia, de la escala de realización, así como de las subescalas relativas a las competencias docentes estudiadas, a través del cálculo del Alfa de Cronbach, muestran niveles elevados de fiabilidad.

El cálculo del Alfa de Cronbach mostró valores elevados en la escala de importancia (Alfa $=0,986)$ como en la escala de realización $(A l f a=0,972)$, en la prueba piloto aplicada a 57 profesores sobre las escalas preliminares. Y del mismo modo, se obtuvieron valores satisfactorios en las escalas de importancia $(\mathrm{Alfa}=, 976)$ y de realización $(A l f a=, 964)$, en la aplicación de la escala definitiva sobre una muestra de la población conformada por 559 profesores.

Los índices de fiabilidad obtenidos por las subescalas relativas a cada competencia docente evaluada fueron también aceptables, tanto en la prueba piloto, como en la aplicación sobre una muestra de la población (Ver tabla 2).

Autoevaluación y reflexión docente para la mejora de la competencia profesional del profesorado en la sociedad del conocimiento. Martínez-Izaguirre, M.; Yániz-Álvarez de Eulate, C. y Villardón-Gallego, L. 


\section{Tabla 2}

\section{Índices de fiabilidad de las escalas y subescalas medidos a través del Alfa de Cronbach}

\begin{tabular}{|c|c|c|c|c|}
\hline \multirow[t]{2}{*}{ ESCALAS } & \multicolumn{2}{|c|}{ APLICACIÓN PILOTO } & \multicolumn{2}{|c|}{$\begin{array}{l}\text { APLICACIÓN } \\
\text { POBLACIÓN }\end{array}$} \\
\hline & Importancia & Realización & Importancia & Realización \\
\hline Escala general & ,986 & ,972 & ,976 & ,964 \\
\hline $\begin{array}{l}\text { Subescala Competencia para la } \\
\text { planificación y gestión educativa }\end{array}$ & ,735 & ,579 & ,692 & ,641 \\
\hline $\begin{array}{l}\text { Subescala Competencia para la gestión e } \\
\text { implementación del curriculum }\end{array}$ & ,925 & ,883 & ,897 & ,854 \\
\hline $\begin{array}{l}\text { Subescala Competencia para la evaluación } \\
\text { educativa. }\end{array}$ & ,924 & ,822 & ,849 & ,809 \\
\hline $\begin{array}{l}\text { Subescala Competencia en orientación y } \\
\text { tutoría. }\end{array}$ & ,898 & ,831 &, 858 & ,794 \\
\hline $\begin{array}{l}\text { Subescala Competencia para el aprendizaje, } \\
\text { la investigación y la innovación. }\end{array}$ & ,899 & ,835 & ,878 & ,835 \\
\hline $\begin{array}{l}\text { Subescala Competencia ética y compromiso } \\
\text { profesional }\end{array}$ & ,873 & ,751 & ,827 & ,788 \\
\hline $\begin{array}{l}\text { Subescala Competencia para la } \\
\text { coordinación docente y trabajo en equipo en } \\
\text { la comunidad educativa }\end{array}$ & ,878 & ,785 & ,820 & ,765 \\
\hline $\begin{array}{l}\text { subescala Competencia para la gestión } \\
\text { emocional y la creación de climas de } \\
\text { confianza }\end{array}$ & ,868 &, 754 & ,790 &, 734 \\
\hline $\begin{array}{l}\text { Subescala Competencia para la } \\
\text { comunicación con la comunidad educativa. }\end{array}$ & 820 & ,797 & & \\
\hline
\end{tabular}

El análisis de los resultados en torno a la fiabilidad de las escalas de importancia como de realización, así como de cada una de las subescalas de importancia y realización de cada competencia estudiada, permitió tomar decisiones sobre la posible mejora y depuración del instrumento. Con el fin de simplificar la escala, sin reducir su fiabilidad y clarificar las dimensiones medidas a través de cada una de las subescalas, y en base a los resultados obtenidos por cada ítem, se tomaron decisiones sobre el mantenimiento, modificación o eliminación de cada uno de ellos.

Por ello, partiendo de una escala preliminar conformada por 86 ítems aplicada en la prueba piloto, la escala definitiva quedó conformada por un total de 65 ítems.

Como se puede apreciar en la Tabla 2, las dos escalas de importancia y realización obtienen un coeficiente alto de consistencia interna. Del mismo modo, lo logran las subescalas de importancia y realización relativas a las diferentes competencias docentes. $\mathrm{La}$ inexistencia de diferencias significativas en las puntuaciones obtenidas entre la prueba piloto y la aplicación a una muestra de la población, refleja la suficiente consistencia interna del instrumento.

Finalmente, fruto de este estudio se obtiene como resultado el instrumento definitivo, la Escala de Evaluación de Competencias Docentes de Educación Obligatoria, que

Autoevaluación y reflexión docente para la mejora de la competencia profesional del profesorado en la sociedad del conocimiento. Martínez-Izaguirre, M.; Yániz-Álvarez de Eulate, C. y Villardón-Gallego, L. 
determina el nivel de importancia que concede el profesorado a las competencias propuestas en su perfil, y su nivel de desarrollo o realización, y favorece el análisis del nivel de discrepancia entre las opiniones y las actuaciones de los docentes a través de las dos escalas que la conforman:

- Escala de importancia de las competencias del perfil docente.

- Escala de realización o aplicación de las competencias docentes.

En la Figura 2 aparecen distribuidos los ítems en función de la competencia docente donde se incluyen.

\section{COMPETENCIAS DOCENTES}

\section{ÍTEMS}

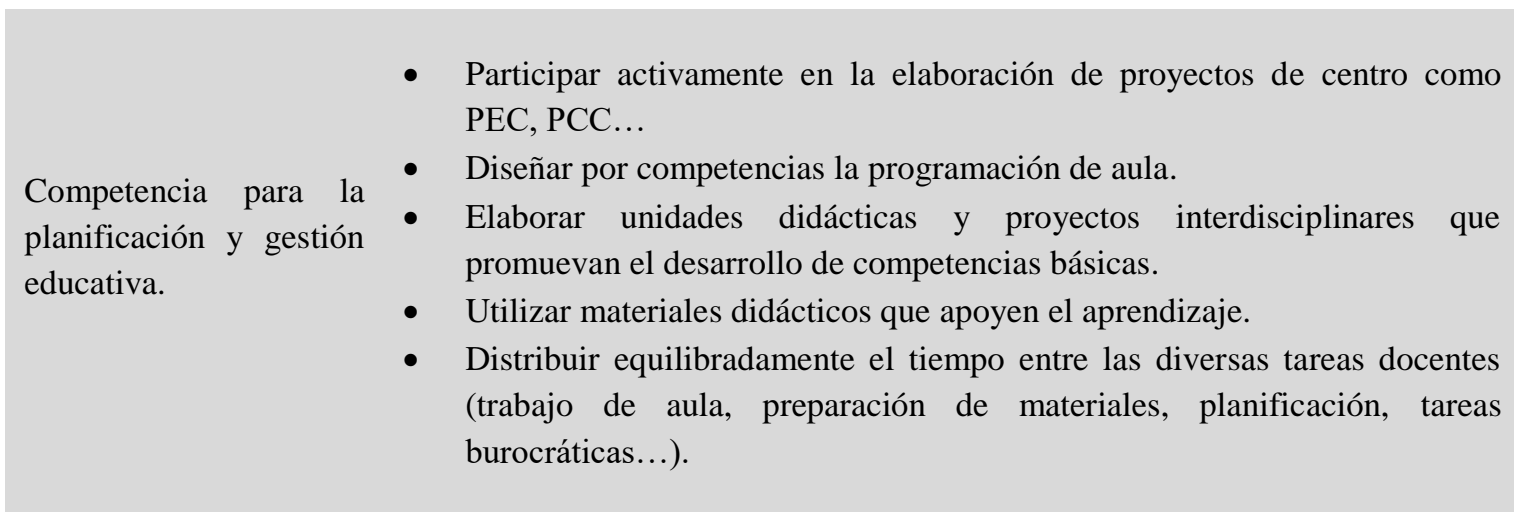

- Aplicar metodologías que promuevan que el alumnado sea activo durante el aprendizaje.

Competencia para la gestión implementación curriculum.
- Realizar actividades que promuevan la cooperación entre los estudiantes.

- Adaptar las actividades a la diversidad de los estudiantes.

- Plantear actividades con distintas soluciones posibles.

- Diseñar actividades cuya resolución requiera el uso de las TIC.

- Idear actividades que requieran el uso de (recursos en) diferentes lenguas.

- Promover en el aula un clima de confianza.

- Potenciar la participación de los alumnos y alumnas en clase.

- Diseñar actividades que despierten en el alumnado interés por aprender.

- Dirigir y dinamizar el trabajo de aula.

- Guiar al alumnado en la realización de tareas de aprendizaje.

- Vincular el aprendizaje a situaciones reales o realistas simuladas.

- Integrar a las familias y otros agentes de la comunidad educativa como apoyo en las actividades de aprendizaje.

- Responder a situaciones novedosas o imprevistas.

- Usar técnicas e instrumentos de evaluación que orienten al alumnado para el desarrollo de competencias.

- Utilizar la evaluación para favorecer el aprendizaje.

Autoevaluación y reflexión docente para la mejora de la competencia profesional del profesorado en la sociedad del conocimiento. Martínez-Izaguirre, M.; Yániz-Álvarez de Eulate, C. y Villardón-Gallego, L. 


\section{COMPETENCIAS}

ÍTEMS

\section{DOCENTES}
Competencia para la
- Evaluar el nivel de competencias tomando como referencia los criterios evaluación educativa. previamente definidos.
- Emplear técnicas de evaluación que permitan evaluar el desempeño de los estudiantes.
- Emplear técnicas e instrumentos de evaluación coherentes con las metodologías de aprendizaje empleadas.
- Ayudar al alumnado a reflexionar sobre las tareas realizadas para que mejore su aprendizaje.
- Comunicar adaptándose a los interesados (alumnado, familia, centro educativo y administración) los resultados de la evaluación.
- Fomentar en el alumnado la autoevaluación y la evaluación entre compañeros.

Competencia orientación y tutoría
- Detectar las necesidades del alumnado para orientarles individual y grupalmente de forma eficaz.

- Favorecer que el alumno se conozca y desarrolle un concepto ajustado de sí mismo.

en - Desarrollar dinámicas que fomenten en el alumnado la confianza en sí mismo y el reconocimiento de sus logros.

- Promover la coordinación educativa con las familias.

- Aplicar actividades que favorezcan entre el alumnado una actitud positiva hacia la diversidad.

- Ayudar al alumnado a conocer y controlar la expresión de sus emociones.

- Aprovechar los conflictos del grupo y del entorno próximo para desarrollar habilidades sociales y actitudes prosociales.

- Colaborar en actividades que ofrezcan un servicio a la comunidad para promover la participación social del alumnado.

- Modificar la acción docente a partir de la reflexión sobre el propio desempeño profesional.

- Reflexionar sobre el propio ejercicio profesional para detectar puntos fuertes y áreas de mejora.

- Analizar los resultados de aprendizaje de los estudiantes para mejorar la propia docencia.

Competencia para el • Estar al día con los contenidos de las disciplinas, en metodologías y en aprendizaje y para la investigación y la innovación recursos didácticos.

- Realizar la formación que me ayude a mejorar la docencia.

- Estar al tanto de la oferta formativa existente para profesorado en activo.

- Buscar recursos en distintos medios (foros, revistas...) para aplicarlos en la tarea docente.

- Participar en proyectos pedagógicos innovadores.

Autoevaluación y reflexión docente para la mejora de la competencia profesional del profesorado en la sociedad del conocimiento. Martínez-Izaguirre, M.; Yániz-Álvarez de Eulate, C. y Villardón-Gallego, L. 


\section{COMPETENCIAS} DOCENTES

\section{ÍTEMS}

- Compartir con colegas las propias experiencias docentes.

- Participar en reuniones o foros sobre innovaciones y experiencias docentes.

Competencia ética y compromiso profesional
- Reflexionar sobre las consecuencias que tienen mis actuaciones docentes en el desarrollo del alumnado.

- Ser consciente de la influencia de mi actuación como docente sobre la realidad social próxima.

- Garantizar la confidencialidad y el buen uso de los resultados obtenidos por el alumnado en las evaluaciones.

- Tener como referencia el marco legal que rige mi profesión.

- Respetar los aspectos confidenciales de mi profesión.

- Actuar como modelo de respeto y consideración hacia todas las personas.

- Actuar de manera justa, equitativa y respetuosa con el alumnado, familias y colegas.

- Evitar cualquier forma de discriminación hacia alumnos, familias y colegas.
Competencia para la coordinación docente y trabajo en equipo en la comunidad educativa
- Asumir las finalidades educativas del centro en que trabajo.

- Trabajar con los miembros del equipo pedagógico en el desarrollo y evaluación de las competencias contempladas en la programación.

- Compartir con el resto del equipo docente normas, pautas de funcionamiento en el aula y el centro, así como métodos de enseñanzaaprendizaje.

- Evaluar las competencias básicas del alumnado compartiendo técnicas e información con otros docentes.

- Participar activamente en los equipos pedagógicos a los que pertenezco.

- Acordar y respetar normas de funcionamiento entre el profesorado y las familias.
Competencia para la gestión eficaz de las emociones y la creación de climas de confianza
- Regular y gestionar eficazmente las propias emociones en el aula.

- Dedicar tiempo a la resolución de problemas que surjan en cualquier situación educativa.

- Relacionarse bien con los colegas.

- Controlar las propias emociones en las tareas realizadas en colaboración con otros agentes educativos (colegas, familias).

- Manejar el estrés ante situaciones cotidianas de esta profesión.

- Generar hábitos que promuevan mi bienestar en el trabajo.

C. para la comunicación

Medida a través de los datos generales aportados sobre los niveles de idiomas

Autoevaluación y reflexión docente para la mejora de la competencia profesional del profesorado en la sociedad del conocimiento. Martínez-Izaguirre, M.; Yániz-Álvarez de Eulate, C. y Villardón-Gallego, L. 


\section{COMPETENCIAS \\ DOCENTES}

ÍTEMS

oral y escrita con la en euskera, inglés, francés y alemán.

comunidad educativa

Figura 2. Ítems de la escala ordenados por competencias docentes

\section{Discusión}

La realidad actual y las necesidades sociales ponen de manifiesto el necesario cambio en el tipo de aprendizajes a promover en la educación básica y en el modo de hacerlo para poder manejarse en la sociedad del conocimiento.

Los cambios sociales obligan a la escuela a reformular sus relaciones con la sociedad si quiere seguir cumpliendo en esencia algunas de las funciones que promovieron su existencia. Si no es así, todas las potencialidades de la educación escolar quedarán en agua de borrajas y la sensación social de pérdida de tiempo irá en aumento (Zabala y Arnau, 2007, p. 71).

Este hecho obliga a reconceptualizar la figura del docente (Escudero et al., 2017), redefinir el tipo de funciones que debe desempeñar y las competencias que deberá movilizar para ello. Asimismo, hace pertinente el diseño de instrumentos de evaluación acordes a este nuevo perfil y de sistemas de evaluación docente que contribuyan a allanar el camino hacia la implementación de tales competencias docentes en el día a día de los centros educativos.

El análisis de las diferentes propuestas diseñadas por la investigación educativa para su promoción y la constatación de la necesidad de avanzar en el estudio del perfil docente, deriva en la construcción de una escala que promueve la autoevaluación y la reflexión del profesorado sobre la importancia de las competencias asociadas a su labor y sobre su nivel de movilización en la acción. La Escala de competencias docentes del profesorado de educación obligatoria, basada en el perfil acorde a la realidad actual y previamente validado (Martínez-Izaguirre et al., 2017), se propone como instrumento para la mejora de la calidad docente. Ésta se compone de dos escalas diferenciadas: la Escala de Importancia, que mide la relevancia otorgada por el profesorado a las competencias docentes y la Escala de Realización, que permite conocer la percepción que tienen los docentes sobre su nivel de competencia.

Esta escala supone un avance en la concepción de la evaluación docente, pues supera la evaluación tradicional de la docencia centrada en analizar la planificación educativa realizada, la metodología y evaluación implementadas o las habilidades docentes para la gestión del aula. La escala diseñada ofrece la oportunidad al profesorado de autoevaluar, además de estas dimensiones básicas, todas aquellas actuaciones necesarias en el seno

Autoevaluación y reflexión docente para la mejora de la competencia profesional del profesorado en la sociedad del conocimiento. Martínez-Izaguirre, M.; Yániz-Álvarez de Eulate, C. y Villardón-Gallego, L. 
de una organización educativa, y que encadenadamente, favorecen la adaptación de la acción a las necesidades educativas vigentes. Por tanto, se contemplan en ella acciones docentes que visibilizan competencias fundamentales para el profesorado pendientes aún de evaluar, como la coordinación para la implementación de proyectos conjuntos, la ética y el compromiso profesional, la gestión eficaz de las emociones, la orientación autónoma hacia el aprendizaje permanente y la investigación o la comunicación eficaz con los diferentes agentes implicados en el hecho educativo.

Por otra parte, la principal contribución de esta escala reside en que su aplicación facilita al profesorado avanzar en su desarrollo profesional y en la mejora de su competencia docente, pues permite:

- Conocer e identificar qué competencias docentes son indispensables para el ejercicio profesional en el contexto educativo actual, y las acciones concretas que favorecen su implementación en la práctica diaria. Conceptualizar e interiorizar el perfil necesario para responder a las exigencias educativas actuales, es un paso indispensable para adaptar la labor docente a los retos educativos de hoy.

- Obtener una fotografía clara que visualice las prioridades educativas de los docentes, así como las acciones realmente realizadas en la práctica cotidiana, tanto de manera individual como colectiva. Esto es posible a través del empleo de la Técnica AIR, que permite posicionar cada competencia, en función de las puntuaciones obtenidas en importancia y realización, en uno de los siguientes cuadrantes: área de baja prioridad, área de sobre-esfuerzo, área de concentración de esfuerzos y área de mantenimiento.

Además, permite determinar de manera ágil el nivel de importancia otorgado a las competencias docentes y su nivel de implementación, tanto globalmente como atendiendo de manera pormenorizada a cada una de las dimensiones que las conforman. La claridad en la representación de los resultados facilita la aportación de recomendaciones para mejorar la práctica (Kitcharoen, 2004).

- Sin olvidar la existencia de exigencias políticas, sociales o normativas para mejorar la competencia profesional de los docentes, la aplicación de la escala propuesta permite al profesorado poner el foco en sus propias necesidades. La herramienta posibilita al docente conocer su percepción sobre la profesionalidad docente y cómo se sitúa ante ella. Además, le ayuda a identificar sus puntos fuertes y débiles, a reflexionar sobre ellos y articular acciones de mejora que contribuyan a su equilibración. La posibilidad de identificar las tareas a las que se les dedica más esfuerzo del necesario, así como tareas de relevancia que

Autoevaluación y reflexión docente para la mejora de la competencia profesional del profesorado en la sociedad del conocimiento. Martínez-Izaguirre, M.; Yániz-Álvarez de Eulate, C. y Villardón-Gallego, L. 
quedan pendientes de llevar a cabo facilitará la propuesta de orientaciones de mejora realistas y eficaces. Es decir, encadenar procesos de mejora desde la propia experiencia y ajustados a situaciones concretas resulta indispensable para establecer cambios significativos y de éxito.

- Por otro lado, la comparativa que permite realizar la Técnica AIR entre el cuadro obtenido a nivel individual con el que refleja el posicionamiento global de un claustro de profesores, o de un conjunto más amplio, permite reflexionar al docente sobre sus sinergias o divergencias con respecto al proyecto docente compartido, y sobre los posibles o necesarios pasos a dar para mejorar la educación ofrecida al alumnado.

El respaldo del juicio de expertos y los análisis de fiabilidad llevados a cabo tanto del diseño preliminar como del diseño definitivo, suponen la constatación de que se cuenta con una herramienta útil, válida y fiable al servicio del perfeccionamiento docente.

Dada la diversidad de funciones y tareas que debe desempeñar el profesorado, así como el tiempo que destina a la docencia directa y a tareas de planificación, gestión y coordinación docente, se ha priorizado la construcción de un instrumento que ofrezca información esencial para la reflexión de manera rápida y sin la necesidad de dedicar mucho tiempo y esfuerzo en ello. La escala presenta una serie de acciones que reflejan el nivel de movilización de conocimientos, habilidades y actitudes en contextos cotidianos que permiten al profesorado afrontar satisfactoriamente sus funciones y, por tanto, cotejar el nivel de aplicación de las competencias en el ejercicio docente.

En definitiva, el empleo de herramientas como la que se ha diseñado y presentado en este estudio ofrece oportunidades al profesorado para pararse a pensar sobre el sentido de su profesión, su papel y responsabilidad en la educación de los futuros ciudadanos, le permite detectar sus áreas de mejora y establecer planes de acción para avanzar en su desarrollo profesional. Estudios como el realizado por Marchesi y Martín (2014) avalan la pertinencia de emplear la reflexión sobre la acción docente para encauzar procesos de mejora, y favorecer el desarrollo profesional de los docentes, permitiendo así el ajuste de su acción profesional al escenario educativo actual. También se cita la conveniencia de desarrollar la práctica reflexiva desde la formación inicial de los docentes (Fenstermacher 1978,1986; citado por Shulman, 2005).

Por ello, se consolida la conveniencia de que el profesorado asuma la responsabilidad para investigar de manera crítica y sistemática sobre su propia práctica (Eirín, García, y Montero, 2009), así como la pertinencia de ajustar el perfil a las necesidades reales para la promoción de aprendizajes eficaces en el aula (Cook-Sather, 2009). Asimismo, la reflexión y la autoevaluación se perfilan como caminos inexcusables para la mejora y el desarrollo docente (Bolancé et al., 2013; Charlier, 2005; Schön, 1983).

Autoevaluación y reflexión docente para la mejora de la competencia profesional del profesorado en la sociedad del conocimiento. Martínez-Izaguirre, M.; Yániz-Álvarez de Eulate, C. y Villardón-Gallego, L. 
Aunque se ha seleccionado la autoevaluación y los procesos de reflexión docente por su poder de acción sobre la mejora de la docencia, se deben advertir y superar, también, algunos de los riesgos que la amenazan (Day, 2007):

- Las múltiples tareas y responsabilidades docentes reducen su capacidad y motivación hacia la reflexión.

- Las coordinaciones impuestas para el tratamiento de aspectos burocráticos impiden la verdadera colaboración docente, y, por tanto, la reflexión conjunta para la mejora de los procesos educativos.

- El ritmo de trabajo que impide la práctica reflexiva, genera sentimientos de culpa que restan aún más la posibilidad de una reflexión constructiva.

- Falta de tiempo real y percibido.

- Se requiere el desarrollo de rutinas que dirijan al profesorado hacia una práctica de la reflexión.

A pesar de estas dificultades, y con la conciencia de que el objetivo primordial de toda evaluación debe ser la mejora, la propuesta realizada, centrada en un modelo de evaluación basado en la reflexión, ofrece importantes usos y oportunidades:

- Individualmente, detectar de manera sencilla los puntos débiles o áreas de mejora, así como las acciones y tareas que resultan indispensables para garantizar el logro de las finalidades educativas.

- Reflexionar de manera conjunta sobre las actuaciones docentes en el seno de una organización educativa, contrastando la coherencia entre las prioridades educativas y los niveles de competencia del profesorado que conforma su claustro, para distribuir tareas y responsabilidades de centro atendiendo a las fortalezas y a los perfiles del profesorado, ajustar y/o elaborar planes estratégicos para abordar aquellas funciones docentes que se observen débilmente tratadas, ajustar los tiempos en función de la relevancia de las diferentes tareas y acciones docentes, así como para establecer planes de formación y asesoramiento acordes a las necesidades reales que presenta el claustro. Se puede convertir, por tanto, en un instrumento facilitador de la mejora y el aprendizaje en las organizaciones educativas, orientando a las escuelas a convertirse en organizaciones que aprenden.

- Analizar si las acciones planificadas a nivel personal o de centro para mejorar ciertas competencias y funciones docentes son realmente efectivas, respondiendo periódicamente la escala y contrastando la evolución en las diferentes dimensiones contempladas en ésta.

Autoevaluación y reflexión docente para la mejora de la competencia profesional del profesorado en la sociedad del conocimiento. Martínez-Izaguirre, M.; Yániz-Álvarez de Eulate, C. y Villardón-Gallego, L. 
- Permitir al profesorado obtener evidencias sobre su eficacia y orientarle a tomar medidas que favorezcan su desarrollo profesional y su bienestar docente.

- Dar luz sobre las verdaderas necesidades formativas del colectivo.

- Contribuir al desarrollo del hábito de la reflexión y autoevaluación docente, esencial para el autoperfeccionamiento y mejora de la competencia docente.

A modo de consideración final, en el momento actual el profesorado ve condicionada su actividad profesional por nuevas situaciones educativas relacionadas con el imparable ritmo de avance del conocimiento, fruto de la diversidad de recursos tecnológicos al alcance que facilitan su acceso y ampliación, y por un paradigma pedagógico que entiende la figura del docente no como un transmisor de conocimiento, sino como facilitador del aprendizajes activos, significativos y transferibles a nuevos contextos (Tórrego, 2008; Villalobos, Torres, y Barona, 2016) en el seno de una comunidad educativa. Ante esta realidad, los esfuerzos por avanzar en la creación de herramientas y procesos que faciliten las adaptaciones de las actuaciones docentes a las necesidades educativas de los estudiantes han de ser intensos y constantes.

Presentación del artículo: 15 de noviembre de 2017 Fecha de aprobación: 17 de enero de 2018 Fecha de publicación: 31 de enero de 2018

Martínez-Izaguirre, M., Yániz-Álvarez de Eulate, C. y Villardón-Gallego, L. (2018). Autoevaluación y reflexión docente para la mejora de la competencia profesional del profesorado en la sociedad del conocimiento. RED. Revista de Educación a Distancia, 56. Consultado el (dd/mm/aaaa) en http://www.um.es/ead/red/56/martinez_et_al.pdf

\section{Financiación}

Esta investigación no ha recibido ninguna subvención específica de los organismos de financiación en los sectores públicos, comerciales o sin fines de lucro.

\section{Referencias}

Ábalo, J., Varela, J. y Rial, A. (2006). El análisis de importancia-valoración aplicado a la gestión de servicios. Psicothema, 18(4), 730-737.

Airasian, P. W., y Gullickson, A. R. (1998). Herramientas de autoevaluación del profesorado. Bilbao: Ediciones Mensajero. Universidad de Deusto.

Autoevaluación y reflexión docente para la mejora de la competencia profesional del profesorado en la sociedad del conocimiento. Martínez-Izaguirre, M.; Yániz-Álvarez de Eulate, C. y Villardón-Gallego, L. 
Altet, M. (2005). La competencia del maestro profesional o la importancia de saber analizar la prácticas. En L. Paquay, M. Altet, E. Charlier, y P. Perrenoud, La formación profesional del maestro. Estrategias y competencias (págs. 33-48). México: Fondo de Cultura Económica.

Aquino, S. P., Izquierdo, J., y Echalaz, B. L. (2013). Evaluación de la práctica edicativa: una revisión de sus bases conceptuales. Revista Electrónica Actualidades Investigativas en Educación, 13(1), 1-21. Recuperado de: http://revista.inie.ucr.ac.cr/uploads/tx_magazine/evaluacion-practica-docenterevision-bases-conceptuales-aquino-izquierdo-echalaz.pdf.

Araya, C., y Vargas, E. (2013). Evaluación docente. ¿Mecanismo equitativo y confiable o proceso viciado que no cumple con su objetivo? Revista Electrónica Actualidades Investigativas en Educación, 13(1), 1-31. Recuperado de: http://revista.inie.ucr.ac.cr/uploads/tx_magazine/evaluacion-docentemecanismo-equitativo-confiable-proceso-viciado-no-cumple-objetivo-arayavargas.pdf.

Barca, A., Peralbo, M., Brenlla, J. C., y Seijas, S. (2006). Una aproximación a los estilos de enseñanza de los profesores de Educación Secundaria. La escala CAPE como instrumento de evaluación. Revista Galego-portuguesa de Psicoloxia e Educación, 13(11-12), 353-362.

Bolancé, J., Cuadrado, F., Ruiz Suárez, J. R., y Sánchez Velasco, F. (2013). La autoevaluación de la práctica docente como herramienta para la mejora del proceso de enseñanza y aprendizaje del alumnado. Avances en supervisión educativa. Revista de la Asociación de Inspectores de Educación de España(18), 1-16. Recuperado de: http://www.adide.org/revista/images/stories/revista18/ase18_art10.pdf.

Bolívar, A. (2008). Evaluación de la práctica docente. Una revisión desde España. Revista Iberoamericana de Evaluación Educativa, 1(2), 56-74.

Cacheiro, M. L. (2011). Recursos educativos TIC de información, colaboración y aprendizaje. Pixel-Bit. Revista de Medios y Educación(39), 69-81.

Charlier, E. (2005). Former des enseignants-professionnels pour une formation continuée articulée à la pratique. En L. Paquay, M. Altet, E. Charlier, y F. Perrenoud, Former des enseignants professionnels.Quelles stratégies? Quelles compétences? (págs. 97-117). Namur: Facultés Universitaires Notre-Dame de la Paix.

Coloma, C. R. (2010). Estudio comprensivo sobre la evaluación del docente. Revista Iberoamericana de Evaluación Educativa, 3(1), 60-76.

Autoevaluación y reflexión docente para la mejora de la competencia profesional del profesorado en la sociedad del conocimiento. Martínez-Izaguirre, M.; Yániz-Álvarez de Eulate, C. y Villardón-Gallego, L. 
Cook-Sather, A. (2009). Translation: an alternative framework for conceptualizing and supporting school reform efforts. Educational Theory, 59(2), 217-231.

CORD. (2005). Teaching Style Inventory. Recuperado de: http://www.texascollaborative.org/tools/TSI.pdf.

Day, C. (2007). Pasión por enseñar. La identidad personal y profesional del docente y sus valores. Madrid: Narcea. Educadores XXI.

De Juanas, A. (2011). Aproximaciones teóricas sobre las competencias del profesorado de Educación Superior. Tendencias Pedagógicas(18), 233-250.

De Ketele, J. M. (2008). Enfoque socio-histórico de las competencias en la enseñanza. Profesorado. Revista de curriculum y formación del profesorado, 12(3), 1-12.

De Ketele, J. M. (2009). Harmonizing the educational globe. World policy, cultural features and the challenges to educational research. Profesorado. Revista de curriculum y formación del profesorado, 13(2), 1-12.

De la Fuente, J., y Martínez Vicente, J. M. (2004). EIPEA. Escalas para la evaluación interactiva del proceso de enseñanza-aprendizaje. Versión para el profesor/a. Madrid: EOS.

Díaz Alcáraz, F. (2007). Modelo para autoevaluar la práctica docente. Las Rozas: Walters Kluwer.

Eirín, R., García, H. M., y Montero, L. (2009). Desarrollo profesional y profesionalización docente. Perspectivas y problemas. Profesorado. Revista de curriculum y formación del profesorado, 13(2), 1-14.

Elizalde, L., y Reyes, R. (2008). Elementos clave para la evaluación del desempeño de los docentes. REDIE. Revista Electrónica de Investigación Educativa, Especial, 1-13. Recuperado de: http://www.redalyc.org/pdf/155/15511127004.pdf.

Escudero, J. M., Cutanda, M. T., y Trillo, J. F. (2017). Aprendizaje docente y desarrollo profesional del profesorado. Profesorado. Revista de curriculum y formación del profesorado, 21(2), 83-102.

Escudero, T., y Correa, A. D. (2006). Investigación en innovación educativa: algunos ámbitos relevantes. Madrid: La Muralla.

García Ramos, J. M., y Congosto, E. (2000). Evaluación y Calidad del Profesorado. En T. González Ramírez, Evaluación y Gestión de la Calidad Educativa. Un Enfoque Metodológico (págs. 127-157). Málaga: Aljibe.

Autoevaluación y reflexión docente para la mejora de la competencia profesional del profesorado en la sociedad del conocimiento. Martínez-Izaguirre, M.; Yániz-Álvarez de Eulate, C. y Villardón-Gallego, L. 
García, B., Loredo, J., Luna, E., y Rueda, M. (2008). Modelo de evaluación de competencias docentes para la Educación Media y Superior. Revista Iberoamericana de Evaluación Educativa, 1(3), 96-108.

García-Peñalvo, F. J., y Ramírez Montoya, M. S. (2017). Aprendizaje, Innovación y Competitividad: La Sociedad del. RED. Revista de Educación a Distancia(52). doi:http://dx.doi.org/10.6018/red/52/1

Garrido, O., y Fuentes, P. (2008). La evaluación docente. Un aporte a la reconstrucción de prácticas pedagógicas más efectivas. Revista Iberoamericana de Evaluación Educativa, 1(2), 125-136.

Hernández Prudencio, M., y Sarramona, J. (2002). La autoevaluación docente. Una propuesta para la Formación Profesional. Bordón. Revista de Pedagogía, 54(4), 559-576.

Hervás, R. M. (2003). Estilos de enseñanza y aprendizaje en escenarios educativos. Granada: Grupo Editorial Universitario.

Jerónimo Montes, J. (2003). Una experiencia de Formación de docentes para la Educación a Distancia Digital. RED. Revista de Educación a Distancia(8), 0.

Kitcharoen, K. (2004). The Importance-Performance Analysis of service quality in administrative departments of private universities in Thailand. ABAC Journal, 24(3), 20-46.

Lieberman, M., y Wilkins, E. A. (2006). The professional development pathways model: from policy to practice. Kappa Delta Pi Record, Spring, 124-128. Recuperado de: http://devtqsource.airws.org/issueforums/plantoAction/resources/4_PDResearchPolicyAct ion/PDPathwaysModel.pdf.

Marchesi, A., y Martín, E. (2014). Calidad de la enseñanza en tiempos de crisis. Madrid: Alianza Editorial.

Martilla, J., y James, J. (1977). Importance-Performance Analysis. Journal of Marketing(41), 77-79.

Martínez-Izaguirre, M., Yániz-Álvarez de Eulate, C., y Villardón-Gallego, L. (2017). Competencias profesionales del profesorado de educación obligatoria. Revista Iberoamericana de Educación(74), 171-192.

Marzo, M., Esteban, L., y Gargallo, A. (2006). ¿Inciden las nuevas te.cnologías en los resultados alcanzados por los alumnos? Un estudio exploratorio. Revista de Educación(340), 695-711.

Autoevaluación y reflexión docente para la mejora de la competencia profesional del profesorado en la sociedad del conocimiento. Martínez-Izaguirre, M.; Yániz-Álvarez de Eulate, C. y Villardón-Gallego, L. 
Méndez Hinojosa, L. M., y González Ramírez, M. T. (2011). Escala de estrategias docentes para aprendizajes significativos: diseño y evaluación de sus propiedades psicométricas. Revista Electrónica Actividades Investigativas en Educación, 11(3), 1-39. Recuperado de: http://revista.inie.ucr.ac.cr/uploads/tx_magazine/escala-estrategias-docentesaprendizajes-significativos-mendez-gonzalez_01.pdf.

Montero, L., y Gewerc, A. (2010). De la innovación deseada a la innovación posible. Escuelas alteradas por las TICs. Profesorado.Revista de Curriculum y Formación del Profesorado, 14(1), 303-318.

Muñoz Cantero, J. M., Rios De Deus, M. P., y Abalde, E. (2002). Evaluación docente vs. evaluación de la calidad. Revista Electrónica de Investigación y Evaluación Educativa, 8(2), 103-134. Recuperado de: http://www.uv.es/RELIEVE/v8n2/RELIEVEv8n2_4.pdf.

Nieto, J. M. (1994). La autoevaluación del profesor. Madrid: Escuela Española.

Nottis, K., Feuerstein, A., Murray, J., y Adams, D. (2000). The teahcer belief inventory: Measuring the theoretical and practical orientations of preservice teachers. Education, 121(1), 90-101.

Padrón Hernández, M. (1994). Cuestionario de satisfacción profesional docente. Tesis doctoral. San Cristóbal de La Laguna, Santa Cruz de Tenerife: Universidad de La Laguna.

Pena, M., Rey, L., y Extremera, N. (2012). Bienestar personal y laboral en el profesorado de Infantil y Primaria: diferencias en función de su inteligencia emocional y del género. Revista de Psicodidáctica, 17(2), 341-360.

Pratt, D. D., y Collins, J. B. (2000). The Teaching Perspectives Inventory (TPI). En T. J. Sonk, V. L. Chapman, y R. St. Clair, Procedings of the 41st Annual Adult Educacion Research Conference (págs. 346-350). Vancouver: Department of Educational Studies. University of British Columbia.

Pratt, D. D., Collins, J. B., y Jarvis Selinger, S. (2001). Development and Use of The Teaching Perspectives Inventory (TPI). AERA. Recuperado de: https://facultycommons.macewan.ca/wp-content/uploads/TPI-onlineresource.pdf.

Rogríguez Carbajal, C. K., y Vera, J. A. (2007). Evaluación de la práctica docente en escuelas urbanas de Educación Primaria en Sonora. Revista Mexicana de Investigación Educativa, 12(35), 1129-1151.

Autoevaluación y reflexión docente para la mejora de la competencia profesional del profesorado en la sociedad del conocimiento. Martínez-Izaguirre, M.; Yániz-Álvarez de Eulate, C. y Villardón-Gallego, L. 
Rueda, M. (2009). La evaluación del desempeño docente: consideraciones desde el enfoque por competencias. Revista Electrónica de Investigación Educativa, 11(2), 1-16. Recuperado de: http://redie.uabc.mx/vol11no2/contenidorueda3.html.

Ruyter, D. J., y Kole, J. J. (2010). Our teachers want to be the best: on the necessity of intra-professional reflection about moral ideals of teaching. Teachers and Teaching: theory and practice, 16(2), 207-218.

Sánchez Prieto, J. C., Olmos Migueláñez, S., y García-Peñalvo, F. J. (2017). ¿Utilizarán los futuros docentes las tecnologías móviles? RED. Revista de Educación a Distancia(52). doi: http://dx.doi.org/10.6018/red/52/5

Schön, D. A. (1983). The reflective practitioner. How proffesionals think in action . New York: Basic Books.

Shulman, L. S. (2005). Conocimiento y enseñanza: fundamentos de la nueva reforma. Profesorado. Revista de curriculum y formación del profesorado, 9(2), 1-30.

Solabarrieta, J. (1997). Un sistema de autoevaluación para el profesorado de Educación Secundaria Obligatoria. Tesis doctoral. Bilbao: Universidad de Deusto.

Tejada, J., Jurado, P., Navío, A., y Ruiz Bueno, C. (2007). La didáctica en un entorno virtual interuniversitario: experimentación de ECTS apoyados en TIC. Revista de Medios y Educación(30), 95-118. Recuperado de: http://www.redalyc.org/articulo.oa?id=36803009.

Tirado-Morueta, R., y Aguaded-Gómez, J. I. (2014). Influencias de las creencias del profesorado sobre el uso de la tecnología en el aula. Revista de Educación(363), 230-255. doi:10-4438/1988-592X-RE-2012-363-179

Tórrego, J. (2008). El profesor como gestor del aula. En A. De la Herrán, y J. Paredes, Didáctica general : la práctica de la enseñanza en Educación Infantil, Primaria y Secundaria (págs. 197-213). McGraw-Hill: Madrid.

Valdivieso, J. A., Carbonero, M. A., y Martín-Antón, L. J. (2013). La competencia docente autopercibida por profesorado de Educación Primaria: un nuevo cuestionario para su medida. Revista de Psicodidáctica, 18(1), 47-78. DOI: http://dx.doi.org/10.1387/RevPsicodidact.5622 .

Vázquez Atochero, A., y Romero Blanco, M. A. (2014). Evaluación: de proceso social a herramienta educativa : importancia de la evaluación en la mejora del sistema educativo. Madrid: CCS.

Autoevaluación y reflexión docente para la mejora de la competencia profesional del profesorado en la sociedad del conocimiento. Martínez-Izaguirre, M.; Yániz-Álvarez de Eulate, C. y Villardón-Gallego, L. 
Vila, I., y Casares, R. (2009). Educación y sociedad. Una perspectiva sobre las relaciones entre la escuela y el entorno social. Barcelona: ICE-Horsori. Universidad de Barcelona.

Villalobos, M. M., Torres, S. A., y Barona, C. (2016). Competencias docentes y formación de docentes virtuales. Revista de Transformación Educativa(Número temático: Educación mediada por tecnología: alternativas digitales y virtuales), 136-157.

Yániz, C. (1998). Un sistema de autoevaluación y mejora para el profesorado de Educación Primaria. Bilbao: Mensajero.

Zabala, A., y Arnau, L. (2007). 11 ideas clave. Cómo aprender y enseñar competencias. Barcelona: Graó.

Zapata, M. (2015). Evaluación de competencias en entornos virtuales de aprendizaje y docencia universitaria. RED. Revista de Educación a Distancia( 1 (DU)), 1-34. 